\title{
A MODEL PROPOSAL ON THE DETERMINATION OF STUDENT ATTENDANCE IN DISTANCE EDUCATION WITH FACE RECOGNITION TECHNOLOGY
}

\author{
Dr. Durmus OZDEMIR \\ ORCID: 0000-0002-9543-4076 \\ Department of Computer Engineering \\ Kutahya Dumlupinar University \\ Kutahya, TURKEY
}

Mehmet Emin UGUR

ORCID: 0000-0003-2427-3794

Deniz Yildizlari Vocational and Technical Anatolian High School

Ministry of National Education

Kocaeli, TURKEY

Received: 03/03/2020 Accepted: 21/05/2020

\begin{abstract}
The aim of this study is to present a model proposal on determining the student participation rate in synchronous courses given in Learning Management Systems (LMS). Especially in situations where equal opportunities cannot be provided or opportunities are limited, distance education provides benefits for learning anytime and anywhere (ubiquitous learning) with the support of educational technologies. When the literature is examined, thanks to distance education; It is seen that it offers a very advantageous teaching environment in terms of location, time, convenience in accessing the resources needed and cost-benefit. However, when the literature is analyzed, it is found that there is a problem in determining the participation levels and rates of students in the Learning Management Systems used in distance education. Students access the activity or course in LMS using text-based user information and passwords. Unfortunately, it is not possible to determine with the current LMS whether the participant is the real responsible person or he/she is actively/synchronously following the course. In this context, a design model has been presented using face recognition algorithms to determine attendance in distance education, to ensure more active participation and to increase success indirectly. In the proposed model, tests were made using special filters for image processing, and in cases where the number of samples was increased, more than $80 \%$ accuracy was provided. The proposed design model was developed in Visual Studio.Net platform and coded on C\# programming language. SQL server is used as database management system and EmguCV library is used for the image processing stages.
\end{abstract}

Keywords: Face recognition, determining attendance, user identification, course participation, distance education.

\section{INTRODUCTION}

Distance Education is a method of education in which students, teachers and teaching materials in different places are brought together through instructional technologies (Bozkurt, et al., 2015; Gunawardena \& McIsaac, 2013). Inequality of opportunities in educational activities is prevented with distance education. Many individuals from different socio-cultural backgrounds can access interactive content in environments such as LMS (Learning Management Systems) and MOOC (Massive Open Online Courses) in distance education (Liyanagunawardena, Adams, \& Williams, 2013; Shin \& Kang, 2015). Distance education is day by day with development of online course platforms, high-speed internet, user friendly eLearning tools and freely available massive open online courses (MOOCs) (Bozkurt et al., 2015). Not only there is an variation 
of online courses but also many learning management systems (LMS) exist that manage and deliver the educational content by various universities and schools. In cases where attendance is not possible due to temporal and spatial reasons, or where opportunities are limited, distance learning is provided ubiquities learning (at any time and anywhere) using instructional technologies (Norman, Nordin, Din, Ally, \& Dogan, 2015). Planned follow-up of content in distance education environments and the engaging and fluent regulation of the learning process without any restrictions is important for the successful completion of the learning process (Alhabeeb \& Rowley, 2018; Battalio, 2009). The educational materials used in distance education activities should be designed to attract the attention of the students, to provide interaction, have a time period and to be motivated (Chao, Saj, \& Hamilton, 2010; Hsu \& Ching, 2013; Lockwood, 2018). In the literature, there are studies showing that student participation rate is another factor affecting success in distance education (Dalkiran, 2018; Grabe \& Christopherson, 2008; Rumble, 2019). There are also studies showing that participation in the course increases the success in distance education systems as in formal education (Arnab, 2018; Crisp, 2018; Lester, 2018).

Therefore, the instructors can give additional points to the students with high course participation rate. However, in Learning Management Systems used in distance education, it was determined which participation rates of the participants were wrong or misleading. Participants provide access to the event or course by entering user information and passwords in text-based validation systems in LMS or MOOCs. If the user name and password are correct, the system will process the time and knowledge of the student (Kamarga, 2018). Unfortunately, the current LMSs and MOOCs cannot be determined whether the participant is a real person to be trained or whether the student is actively following the course. In this study, it is aimed to determine the attendance of the students accurately and clearly by using image processing methods for LMSs and MOOCs used in distance education. In addition, it will be possible to determine the differences in teachers 'presentation methods and the students' course participation rate changes.

\section{Conceptual Framework and Purpose of the Study}

In existing LMSs used in distance education, students' attendance cannot be controlled in real time. It was observed that the individuals who participated in the course / activities in the LMS could not be identified with the use of text-based user name and password whether they were real persons, and some of them were not interested in the course content offered after logging in and continued their daily work (Newberry, 2013; Ozgol, Sarikaya, \& Ozturk, 2017; Vanslambrouck, Zhu, Lombaerts, Philipsen, \& Tondeur, 2018).

It has been stated in the studies conducted between the years of 2004 and 2018 that the student's active participation rate increases the student's academic success in distance education (DeTure, 2004; Hawkins, Frander, Young, \& Deal, 2017; Newberry, 2013; Shelton, Hung, \& Lowenthal, 2017; Vanslambrouck et al., 2018; Wilson \& Pretorius, 2017). For this reason, it is very important to develop identification procedures and apply different methods in LMS and MOOCs used in distance education. This will also prevent unauthorized persons from using the LMS or MOOCs. In this way, the validity and reliability of the exams will be increased with the integration of the our proposed model into the LMS (Flores, Walters, \& Kiekel, 2018; Ortagus, 2017).

In the 2016-2017 academic year, 871 students studying at four different secondary schools in Ankara/Turkey investigated the effect of students' participation on their academic achievement (Celik, Toraman, \& Celik, 2018). As a result of the research, it was found that there was a positive and high level relationship between cognitive participation and academic achievement. The results of the research showing this relationship are presented in Table 1. 
Table 1. Research Results on the Relationship Between Academic Achievement and Class Participation (Celik et al., 2018)

\begin{tabular}{lll}
\hline Variables & $\mathbf{r}$ & $\mathbf{p}$ \\
\hline Academic Achievement*Sensual Participation & 0,990 & 0,000 \\
Academic Achievement*Behavioral/Class Participation & 0,563 & 0,008 \\
Academic Achievement*Cognitive Participation & 0,993 & 0,000 \\
Academic Achievement*Non-attendance & $-0,329$ & 0,012 \\
\hline
\end{tabular}

When the studies in the literature were examined, a positive correlation was found between general academic achievement and class participation (Battalio, 2009; Howell, Saba, Lindsay, \& Williams, 2004; Knight, Hakel, \& Gromko, 2008; Vanslambrouck et al., 2018; Yukselturk \& Bulut, 2007). Academic success increases as participation increases (Han \& Shin, 2016). Negative correlation was also found between nonattendance and academic achievement. Thus, it is concluded that not attending the course may cause failure.

LMS consist of course presentation and management, interaction, communication, content development and collaboration. LMS such as Open Source Moodle, ATutor, Sakai and Commercially Available Blackboard, Sum Total, Success-Factors have not included system that can detect course attendance with face recognition technology (Anshari, Alas, Hamid, \& Smith, 2016; Krouska, Troussas, \& Virvou, 2017). A Massive Open Online Course (MOOC) is a free online course that supports learning in a variety of different subjects and is open to anyone with access to a computer and the internet (Canbek \& Hargis, 2015). The MOOC actualize a networked environment designed within the context of distance e-learning and potential engagement. In this connection, MOOCs not only been providing equality in educational and instructional opportunities, but also been meeting the demands of higher education in a wider scale like Learning Management Systems. It was thought that apparent advantage of broader access to potentially a MOOC can help revolutionize higher education pedagogy. MOOCs contain items that support the following terms in the literature. Ubiquitous (anytime, anywhere) learning attributes, motivation, direct and timely applications and endless opportunities to repeat conceptual lessons and assessments until mastery is accomplished (Firat, Kilinc, \& Yuzer, 2018). MOOCs aim to connect learners from across the globe with educators and with each other but also it has not included the face detection system in attendance or course paticipation system (AlRahmi, Aldraiweesh, Yahaya, Kamin, \& Zeki, 2019; Chaudhari \& Thakkar, 2019; Lei, Zhou, \& Hu, 2019; Salzmann, Piguet, \& Gillet, 2019).

When the existing distance education systems are examined, it is seen that users can login to the system by using unique keys such as user name, e-mail, phone number, ID number and the passwords they have previously determined (Walker, Lindner, Murphrey, \& Dooley, 2016; Zheng, Wang, Doll, Deng, \& Williams, 2018).

In cases where attendance is controlled, individuals may submit their information to the fake participants and request to attend the course in their own place (Paiva Guimarães et al., 2017; Gräther et al., 2018). Another problem is, when the participant logging to the LMS, they open the course screen and continue their daily work. In the currently used LMS systems, the course attendance process is depending on either live class attendance time or video monitoring. Therefore, although students do not participate actively, but the current LMSs are reported to the student that he/she attended the course.

Due to the fact that the student's participation in the course cannot be determined with full accuracy, only the midterm exams are allowed in distance education programmes in higher education institutions (Bilgic \& Tuzun, 2015; Broadbent \& Poon, 2015). This situation, which is susceptible to abuse, so it needs to be corrected using biometric data and the real participant identified.

In this study, it is aimed to develop a prototype design model for LMS and MOOCs used in distance education and to determine the students' participation to the course by using image processing methods. If the designed system is applied in LMS or MOOCs, the participation rates of the students will be determined. It will also be possible to determine which of the teacher's presentation methods are more motivating or 
increase participation. However, a step will be taken to increase the validity and reliability of the exams which are applied in LMSs and MOOCs. Therefore, this can be a new idea for existing LMSs and MOOCs because in the current systems, the attendance status is evaluated only with the information within the log records. However, in this proposed model of our study, the participation of the user in the course with image processing techniques will be determined.

\section{MATERIALS AND METHODS}

In this section, the software technologies used in the proposed prototype and the method followed in the design process are presented.

\section{OpenCV Library}

OpenCV (Open Source Computer Vision) is used as image processing library/framwork. OpenCV is released under a BSD license and is therefore free for both academic and commercial use. It can be developed with $\mathrm{C}++$, Python and Java programming languages and supports Windows, Linux, Mac OS, iOS and Android operating systems. Therefore, it is thought that the proposed prototype system can be integrated into LMSs developed on different platforms. OpenCV is efficient for computing efficiency and for use in real-time applications (OpenCV Library, 2018).

\section{Assumptions and Limitations}

The application presented in this study is presented as a prototype model. It is assumed that the server systems, technical infrastructure and bandwidth required for integration into multi-user systems. In the proposed model, in accordance with the personal data security laws, it is necessary to allow the use of the images of individuals at the beginning of the program and to obtain their consent. For this reason, in the prototype model prepared in the research, approval was obtained from the user at the entrance of the program.

The limitations of facial recognition systems can be listed as follows (Saxena, Sharma, \& Sharma, 2016). Physical changes: facial expression change, aging, makeup, glasses, beard, hairstyle, mustache. Camera angle changes: The scale changes on the face and plane rotation of the camera, as well as its rotation in depthly. Imaging changes: Lighting variation or camera variations. No existing system or study in the literature can claim that these problems can be overcome $100 \%$ fully.

\section{Development Steps and Method of Proposed Prototype Model}

In this section, the method which is designed and applied in the stages of the proposed system is explained. The system consists of 5 parts. The basic functions and process steps of the proposed model are presented in Figure 1. The application interface was developed using the $\mathrm{C}$ \# programming language on the Microsoft Visual Studio .Net platform. OpenCV framework and EmguCV libraries were used for image processing. SQL Server 2017 software is used for data storage and retrieval. When the literature is examined, eigenfaces recognition algorithm can be used with gaussian, median and laplace filters (Lwin, Khaing, \& Tun, 2016). As the results obtained in our study filters were compared, and the gauss filter was used together with the eigenfaces recognition technique because it provides the best performance.

In this study, the proposed system is designed to be modular and developable. In this way, the new modules that will be added to the application later can be easily integrated into the system. The workflow for the proposed system design is summarized in Figure-1 
1. Saving User Information to the Database

- The face is detected on the camera,

- Fields are checked,

- User information is saved to the database, face file directory, and face tag text file.

. Face Detection and Recognition at Login to the System

- Registered trained faces are added to the face list

- Face is detected by the HaarCascade classifier procedure,

- The detected face is checked in the list of trained faces,

- "The value returned from the "EigenObjectRecognizer" class is the label of the trained face and If the ID number is the same, verification of the participant will be successful.

3. Choosing Course/Training Content

- The courses and their contents in the LMS are listed in this field

-Access and usage records of the participant are displayed and transition to the course/training environment is provided by selecting process.

4. Determination of Classroom Participation Time with WebCam

- As long as the face tag detected on the screen and the ID number at the entrance match, the software detects that attendance and also the attendance graphic is drawn.

5. Saving Session Information to the Database and Reporting

-The participant clicks on "End Session" when the training is completed,

- The start and end times of the session and the active participation time and rate determined by the face are recorded in the database.

Figure 1. Workflow of the proposed system design

Also the architecture of the proposed system is presented in Figure 2. While developing the software, it was given importance to be user-friendly, fast and secure.

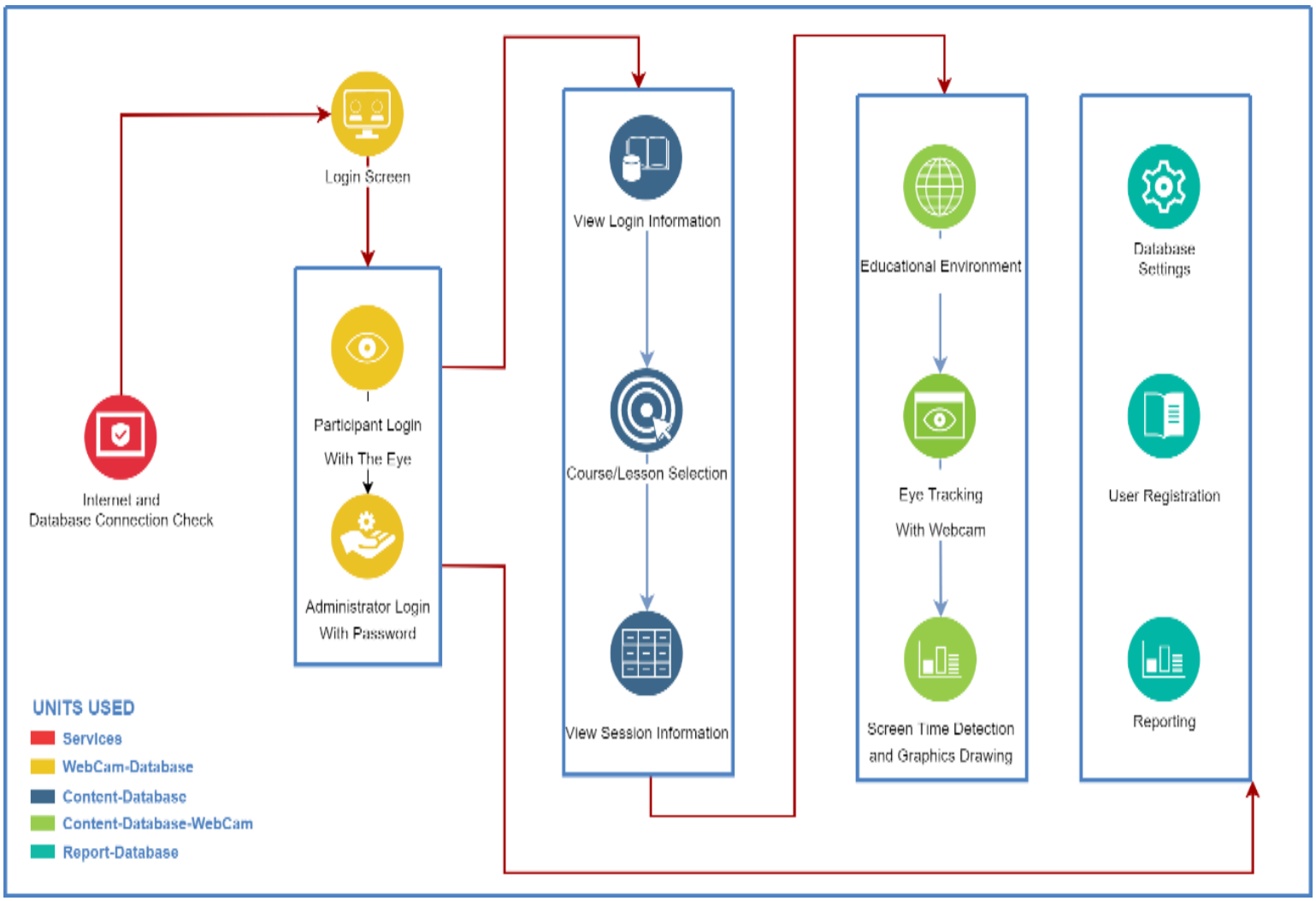

Figure 2. Software architecture of the proposed system 


\section{Login Screen}

On the login screen, both administrator login and user login are included. In this interface, the user, who has the authority to administer, will be able to access the screens to add new participants to the system and make general reporting.

The checkbox and the "Login" button are activated / deactivated in order for the participant to log in to the system and allow the use of their own camera by the system. When the face information of the participant identified and added to the database matches with the ID number, the application switches to the login screen.

\section{Technical Detail}

Timer "timer2" is triggered when the ID number is entered and the "Login" button is clicked. This timer captures snapshots using the "Capture" class in the EmguCV library at intervals of 0.1 seconds. These captured frames are converted to gray color images with the "Convert" method. Then the "Haar Cascade" classifier of the OpenCv library identifies the faces in the images. The "EigenObjectRecognizer" class is used to gather information about the detected face or search the database.

Images trained to search for image matching are called from the relevant folder, and the information of the corresponding tags to the images is called from the relevant text file.

Images and tags are sent to the "EigenObjectRecognizer" class and the result is returned with the "noun" tag. If this "name information" is equal to the information in the entry, the system is logged on. User and administrator sample login screenshots are presented in Figure 3.
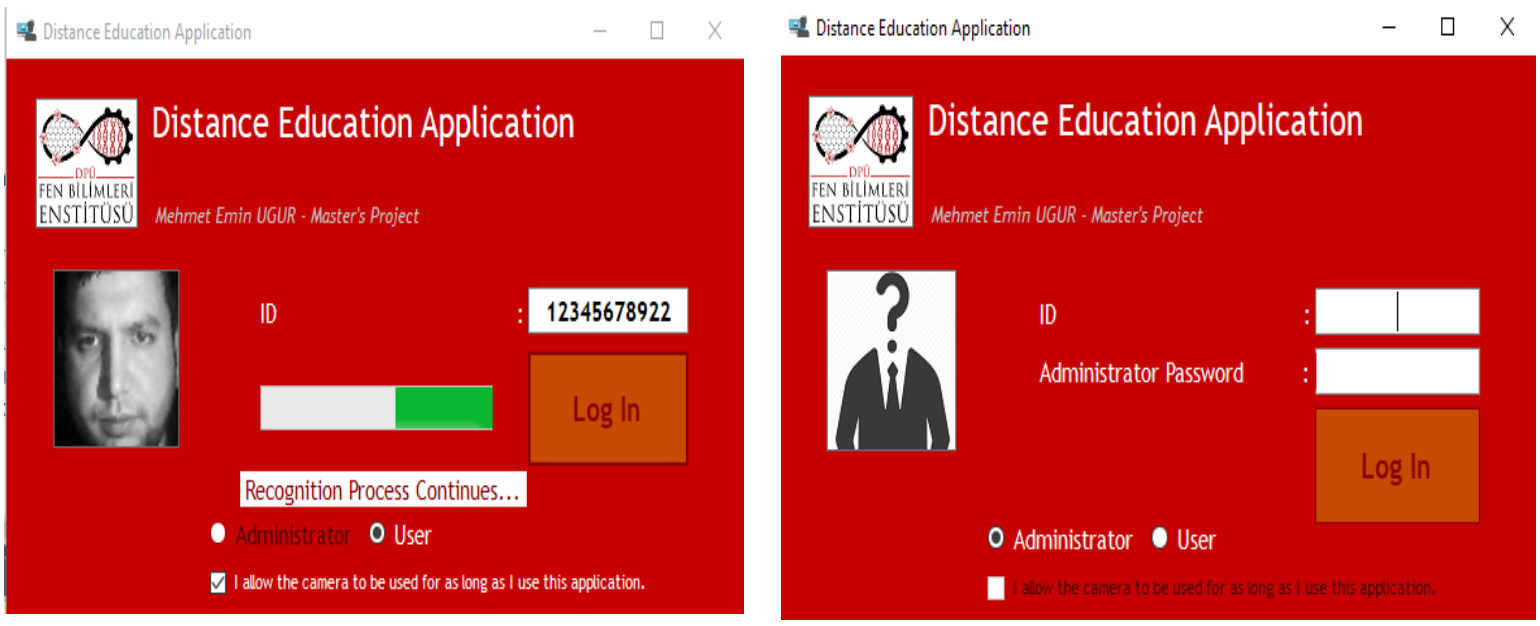

Figure 3. Application login screens for User and Administrator

\section{Login Screen}

This screen displays the information of the user who has entered the software. The ID number, name, surname, date of birth, place of birth, e-mail, telephone and authority levels are listed in the user's database. In this way, the user makes sure that he/she enters the system with the correct information. The screenshot of the login screen is presented in Figure 4. 


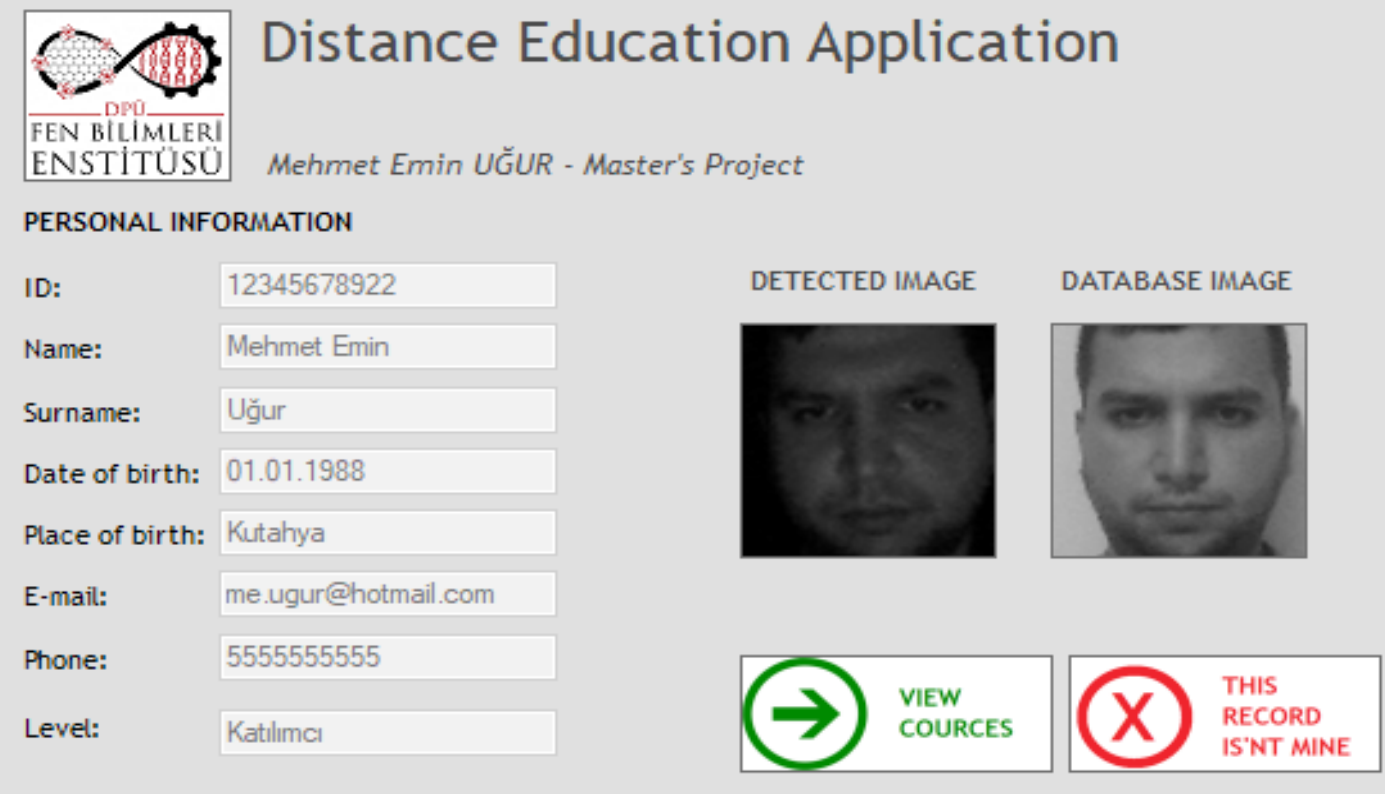

Figure 4. Login screen

\section{Course / Topic Selection Screen}

The courses that the participant can take in the Course / Topic Selection screen are grouped according to the courses. Here, when the relevant course and topic is selected, previous session information is displayed. Depending on the individual's choice, previous session information is pulled from the "session" table with query commands and listed in "datagridview". The course / topic selection screen screenshot is presented in Figure 5.

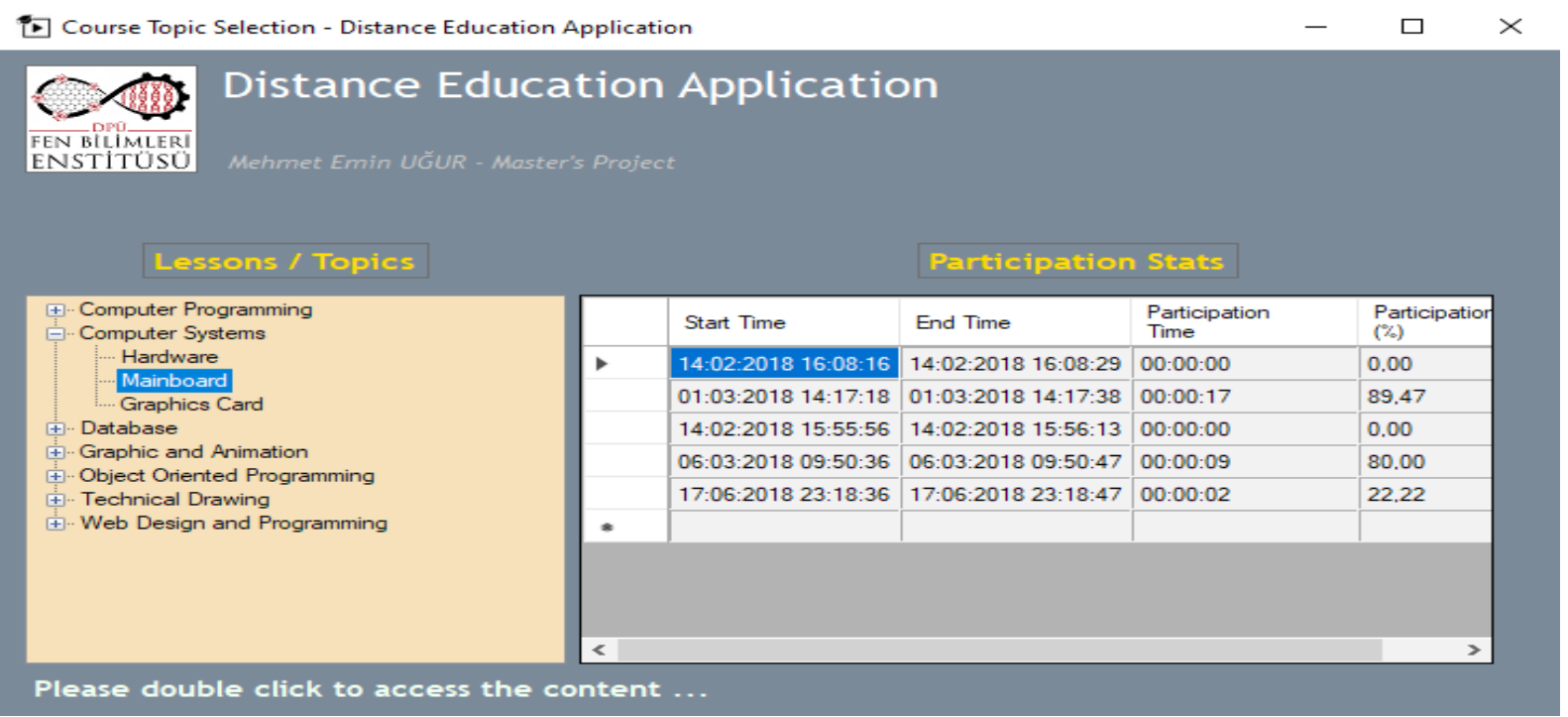

Figure 5. Course / Topic Selection Screen

\section{Course Activity Screen}

This screen shows the distance education course activity in which the participant's face detection is made and the participation rate is shown simultaneously with a graphic and also registered in the database. The course 
title, video and content reflected on the screen are manageable and adding, deleting and editing operations can be performed by the user. The time of the user to watch / look at the lesson is calculated on this screen and reflected on the graph instantly. While ending the session, the calculated time is added to the database. The training screen image is presented in Figure 6.

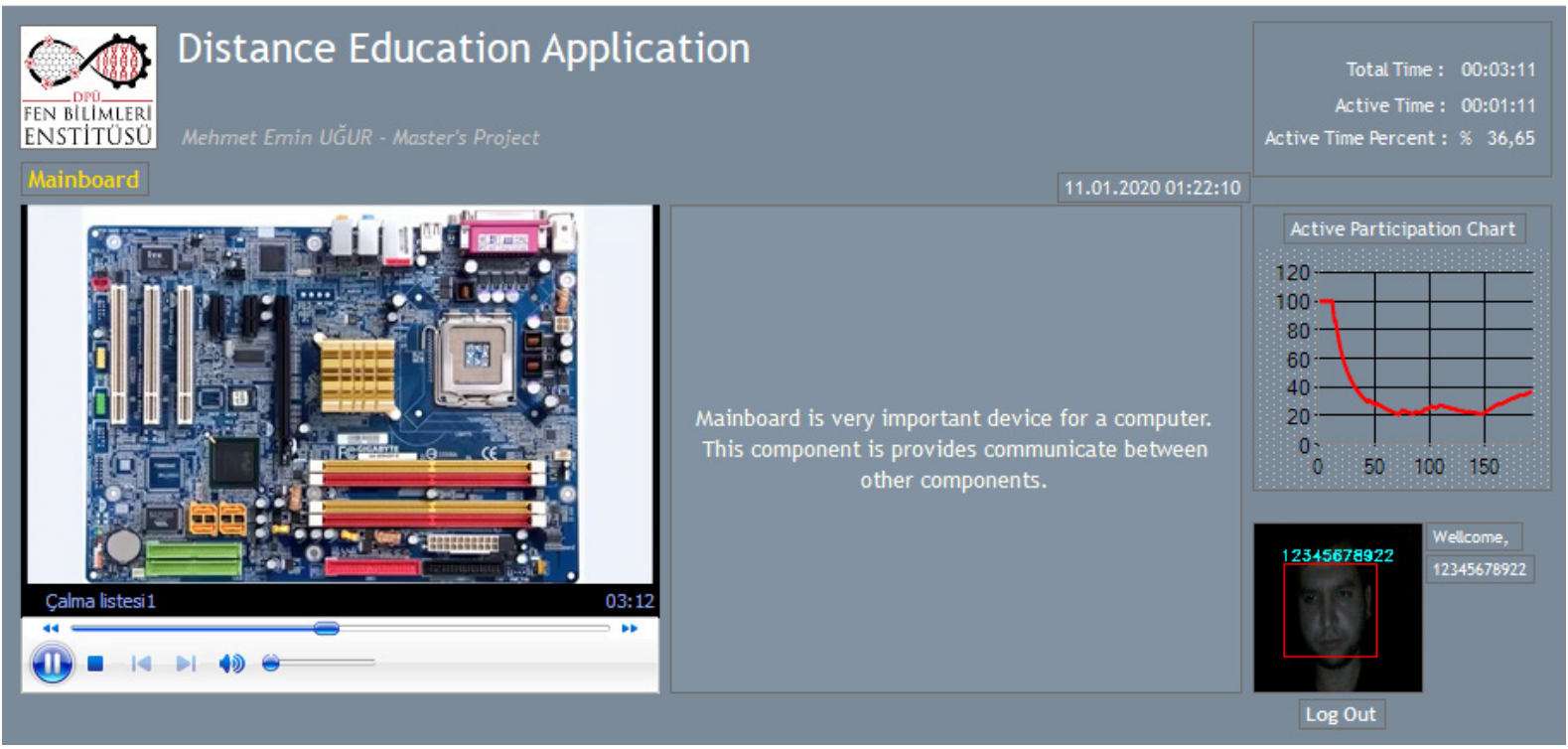

Figure 6. Course Activity Screen

WebCam should be fixed on the screen in order to detect the face in a healthy way. In addition, in order for the system to work properly, WebCam should not be exposed to light directly, but the light should fall on the face of the user. In this form, it captures a snapshot using the "Capture" class in the EmguCV library at intervals of 0.1 seconds. These captured frames are converted to gray color images with the "Convert" method. Immediately afterwards, the "Haar Cascade" classifier of the OpenCv library identifies the faces in the images. The "EigenObjectRecognizer" class is used to gather information about the detected face or search the database.

The snapshot is compared with the ID number and tag of the relevant user in the database and the duration of participation is stored in a variable. The instant participation graph is renewed by calculating the participation rate every second and adding it to the graph. By clicking the "End Session" button on the form; ID number, total time, start and end time, and the current participation rate is recorded in to the database using the created objects. The necessary conditions for correct face recognition are presented in Figure 7.

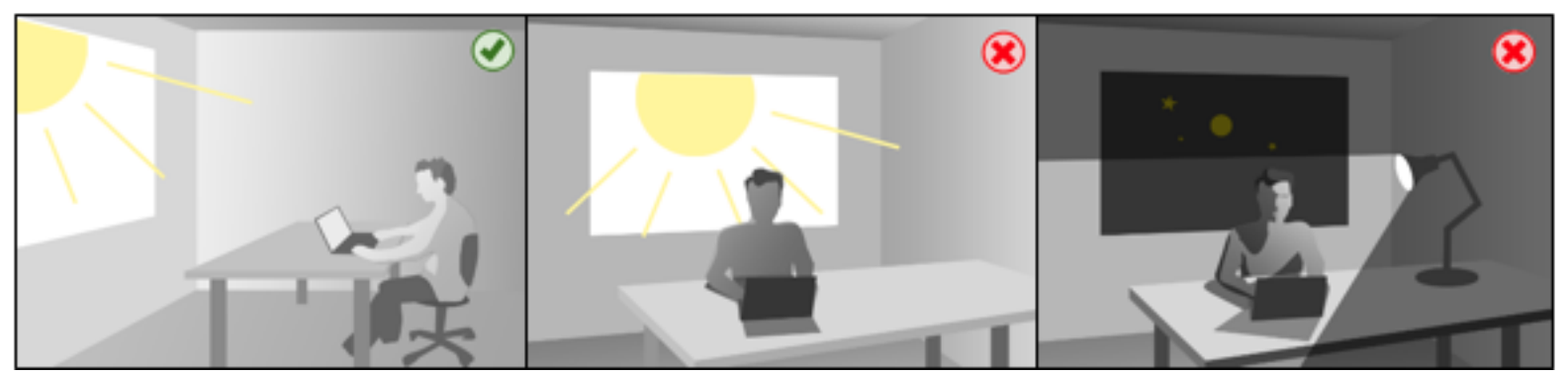

Figure 7. Conditions Required to Achieve High Accuracy in Face Recognition (xLabs Tracker, 2016) 


\section{Report Screen}

This screen contains statistical information about the participants. It is clear that statistical information is also important for the development of the system. The meanings of the fields in this report are as follows. Student's Identity number (ID), starting time of student participation in the related course (Start), student's exit from the related course (End), the time spent by the student in the relevant course or the active participation time of the student (Time), student participation rate, ip address (IP No) and location of the ip address are kept in the database. The screenshot of the report screen is presented in Figure 8.

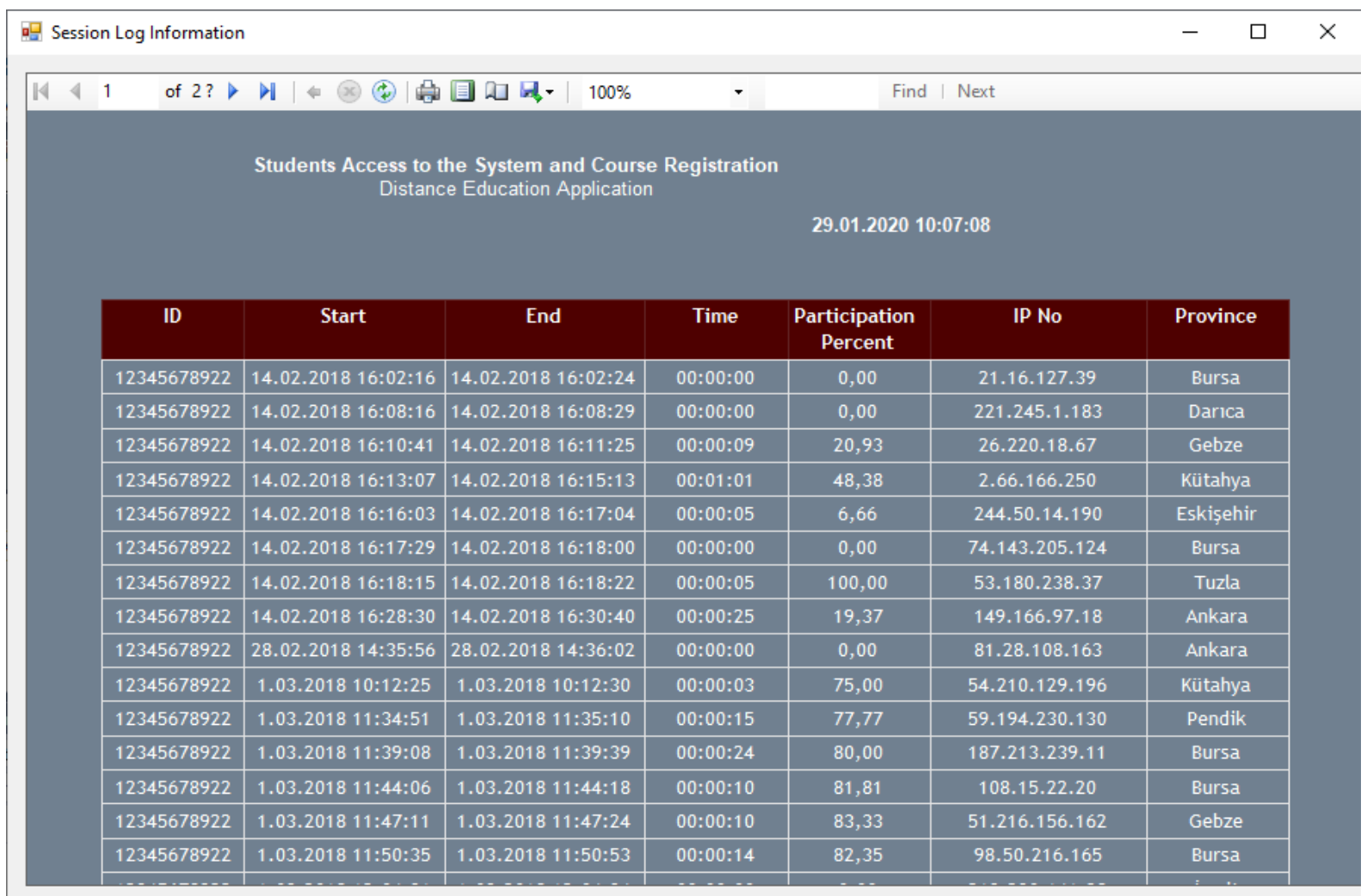

Figure 8. Report Screen

Keeping ip addresses and location information is important for the access security of the participants. Knowing which user accessed the system from which ip address will make it easier to identify possible problems.

\section{DISCUSSION AND RESULTS}

Attendance is very important for every student in the learning process in distance education as in formal education. It gives them an opportunity to expand their knowledge through interaction with their teachers and friends by asking questions. (Martin, Wang, \& Sadaf, 2018; Simonson, Zvacek, \& Smaldino, 2019). Increasing class attendance is essential in the learning process and cannot be avoided by any learning institution. In this study the proposed model can be use to increase class attendance in distance education. With the developed prototype model, the time for individuals to look at the screen can be determined in distance education. Although the time of looking at the screen cannot be presented as a concrete indicator of class participation, it is one of the most binding factors. The determination of the attendance status is considered as an important criterion for the success of the course. Celik et al., (2018) found a positive correlation between affective and cognitive participation and course success. A negative relationship was found 
between not attending the course and the success of the course. Samson, Czarnik, \& Gross (2017) stated that statistical analyses show that several measures of participation including in-class activity participation and number of slides viewed were significantly related to exam scores. As a matter of fact, with our proposed model application, it is foreseen that success will increase when the participation in the class attendance increases. In addition, with this application, some kind of electronic course attendance system will be realized. This situation will be a useful model in the distance education trends period when the instructional technology tools become widespread and even become an integral part of our lives (Bozkurt et al., 2015). Trend technologies like machine learning, smart software systems, image processing and new software technologies changes enterprise learning's status quo with an extraordinary ability to deliver automated and truly personalized learning to completely change the way students learn for the better. Literature studies conducted within the scope of the study show that the student's attendance status has a positive relationship with the course success (Battalio, 2009; Dalkiran, 2018; Sadera, Robertson, Song, \& Midon, 2009; Vanslambrouck et al., 2018). For this reason, with the prototype model, it is predicted that the attendance will increase and indirectly, the success of students will increase.

The most important limitation of the study is the success rate $(80 \%-85 \%)$ in recognition processes due to the insufficient facial recognition algorithms or the light differences in the image area. As a suggestion for future researches, it is recommended to obtain data from eye tracking devices along with the images taken from the camera in order to increase the success level in determining attendance. Thus, it is predicted that the proposed prototype model will contribute to the reduction of the margin of error. The expected effects of this study is that it encourages learners to follow carefully and complete the courses that they start to take, and in this way it is foresighted to boost their learning effects and to facilitate actual learning transfer (Rae \& O’Malley, 2017). And also studies shows that education institutions are searching creative solutions that are developed in distance education course attandance areas. In this connection, the proposed model in this study is given as an alternative for either synchronous or blended approaches where course attendance tracking gets partially uncertain in distance education. In this study, a structural design is provided to determine the attendance status in the learning activities carried out by distance education method through LMSs, MOOCs and other educational management and material platforms.

In this way, it is thought that a solution will be produced to the attendance status system, which is seen as a problem in distance education. In addition, it is foreseen that students' participation in the lessons will increase with this method. Therefore, it will have an indirect effect on academic success. However, it should not be forgotten that, during the login, users should be informed and permitted that the image information is collected and used. It is thought that the model proposal presented in the study will provide a solution to the attendance status problem in distance education and will meet the need in this area.

Authors' Note: This article was produced from the master's thesis prepared by Mehmet Emin UGUR under the supervision of Dr. Durmus OZDEMIR. 


\section{BIODATA and CONTACT ADDRESSES of AUTHORS}

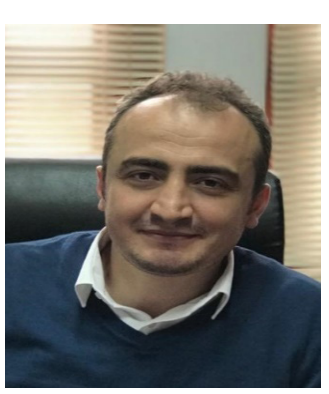

Dr. Durmus OZDEMIR is currently working as an Assistant Professor of Computer Engineering Department at Kutahya Dumlupinar University since May 2016. He gained his PhD degree at Computer Education and Instructional Technologies Department in Ataturk University in April 2015. His research interests are instructional technology integration, digital transformation, e-learning, distance education policies, optimization, data security science, and deep learning. He has various research articles published in international and national indexed journals, book chapters and papers submitted to international meetings. He supervised 6 master theses. He has also contributed research projects.

Durmus OZDEMIR

Department of Computer Engineering, Faculty of Engineering Address: Kutahya Dumlupinar University, 43000, Kutahya, Turkey

Phone: +90 2744434253

E-mail: durmus.ozdemir@dpu.edu.tr

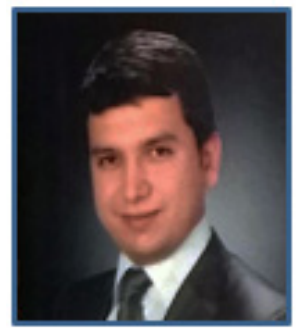

Mehmet Emin UGUR is a teacher at Deniz Yildizlari Vocational and Technical Anatolian High School, Ministry of National Education. He obtained his Master's Degree in the Department of Computer Engineering from Kutahya Dumlupinar University in June 2018. His academic interest areas are distance education, facerecognition systems, eye-tracking systems, and determination participation in the lesson. He did some applications on the internet of things area. He has also participated and presented in national and international conferences.

Mehmet Emin UGUR

Deniz Yildizlari Vocational and Technical Anatolian High School, Ministry of National Education

Address: 41700, Darica, Kocaeli, Turkey

Phone: +90 5558552221,

E-mail: me.ugur@hotmail.com

\section{REFERENCES}

Al-Rahmi, W., Aldraiweesh, A., Yahaya, N., Kamin, Y. Bin, \& Zeki, A. M. (2019). Massive open online courses (MOOCs): Data on higher education. Data in Brief, 22, 118-125.

Alhabeeb, A., \& Rowley, J. (2018). E-learning critical success factors: Comparing perspectives from academic staff and students. Computers \& Education, 127, 1-12.

Anshari, M., Alas, Y., Hamid, M. H. S. A., \& Smith, M. (2016). Learning management system 2.0: Higher education. In Handbook of research on engaging digital natives in higher education settings (pp. 265279). IGI Global.

Arnab, C. (2018). The Absence of Longer Texts in Literature Classes in Some Open and Distance Education Courses in India: Learning Outcomes. International Linguistics Research, 1(1), p95-p95.

Battalio, J. (2009). Success in distance education: Do learning styles and multiple formats matter? The Amer. Jrnl. of Distance Education, 23(2), 71-87.

Bilgic, H. G., \& Tuzun, H. (2015). Yuksekogretim kurumlari web tabanli uzaktan egitim programlarinda yasanan sorunlar. Acikogretim Uygulamalari ve Arastirmalari Dergisi, 1(3), 26-50.

Bozkurt, A., Akgun-Ozbek, E., Yilmazel, S., Erdogdu, E., Ucar, H., Guler, E., ... Goksel-Canbek, N. (2015). Trends in distance education research: A content analysis of journals 2009-2013. International Review of Research in Open and Distributed Learning, 16(1), 330-363. 
Broadbent, J., \& Poon, W. L. (2015). Self-regulated learning strategies \& academic achievement in online higher education learning environments: A systematic review. The Internet and Higher Education, $27,1-13$.

Canbek, N. G., \& Hargis, J. (2015). Educational innovation in e-learning: MOOCs and OER movements in Turkey. Glokalde, 1(1), 19-32.

CELIK, S., TORAMAN, S. O., \& CELIK, K. (2018). The relation of student achievement with course attendance and teacher immediacy. Kastamonu Education Journal, 26(1), 209-217.

Chao, I. T., Saj, T., \& Hamilton, D. (2010). Using collaborative course development to achieve online course quality standards. The International Review of Research in Open and Distributed Learning, 11(3), 106-126.

Chaudhari, K., \& Thakkar, A. (2019). Survey on handwriting-based personality trait identification. Expert Systems with Applications, 124, 282-308. https://doi.org/10.1016/j.eswa.2019.01.028

Crisp, B. R. (2018). From distance to online education: two decades of remaining responsive by one university social work programme. Social Work Education, 37(6), 718-730.

Dalkiran, O. (2018). Investigation of Relationship Between Theoretical Practice Course Success and Attendance. Journal of Education and Training Studies, 6(5), 189-193.

de Paiva Guimarães, M., Alves, B., Martins, V. F., dos Santos Baglie, L. S., Brega, J. R., \& Dias, D. C. (2017). Embedding augmented reality applications into learning management systems. International Conference on Computational Science and Its Applications, 585-594. Springer.

DeTure, M. (2004). Cognitive style and self-efficacy: Predicting student success in online distance education. American Journal of Distance Education, 18(1), 21-38.

Firat, M., Kilinc, H., \& Yuzer, T. V. (2018). Level of intrinsic motivation of distance education students in e-learning environments. Journal of Computer Assisted Learning, 34(1), 63-70.

Flores, S., Walters, N. M., \& Kiekel, J. (2018). Academic Instruction at a distance: An examination of holistic teacher perceptions in a virtual high school. Online Journal of Distance Learning Administration, 21(1).

Grabe, M., \& Christopherson, K. (2008). Optional student use of online lecture resources: resource preferences, performance and lecture attendance. Journal of Computer Assisted Learning, 24(1), $1-10$.

Gräther, W., Kolvenbach, S., Ruland, R., Schutte, J., Torres, C., \& Wendland, F. (2018). Blockchain for education: lifelong learning passport. Proceedings of 1st ERCIM Blockchain Workshop 2018. European Society for Socially Embedded Technologies (EUSSET).

Gunawardena, C. N., \& McIsaac, M. S. (2013). Distance education. In Handbook of research on educational communications and technology (pp. 361-401). Routledge.

Han, I., \& Shin, W. S. (2016). The use of a mobile learning management system and academic achievement of online students. Computers \& Education, 102, 79-89.

Hawkins, A., Frander, E., Young, M., \& Deal, K. (2017). Reflection on Retention: An Evaluation Study on Minority Students' Success in an Online Nursing Program. Perspectives In Learning, 16(1), 5.

Howell, S. L., Saba, F., Lindsay, N. K., \& Williams, P. B. (2004). Seven strategies for enabling faculty success in distance education. The Internet and Higher Education, 7(1), 33-49.

Hsu, Y.-C., \& Ching, Y.-H. (2013). Mobile app design for teaching and learning: Educators' experiences in an online graduate course. The International Review of Research in Open and Distributed Learning, $14(4)$.

Kamarga, H. (2018). Constructing online based history learning: comparison of learning content management system (LCMS) to learning management system (LMS). Historia: Jurnal Pendidik Dan Peneliti Sejarah, 12(2), 255-273. 
Knight, W. E., Hakel, M. D., \& Gromko, M. (2008). The Relationship Between Electronic Portfolio Participation and Student Success. Professional File Number 107, Spring 2008. Association for Institutional Research (NJ1).

Krouska, A., Troussas, C., \& Virvou, M. (2017). Comparing LMS and CMS platforms supporting social e-learning in higher education. 2017 8th International Conference on Information, Intelligence, Systems \& Applications (IISA), 1-6. IEEE.

Lei, Z., Zhou, H., \& Hu, W. (2019). Combining MOOL with MOOC to Promote Control Engineering Education: Experience with NCSLab. IFAC-PapersOnLine, 52(9), 236-241.

Lester, S. (2018). Sequential schooling or lifelong learning? International frameworks through the lens of English higher professional and vocational education. Education+ Training, 60(2), 213-224.

Liyanagunawardena, T. R., Adams, A. A., \& Williams, S. A. (2013). MOOCs: A systematic study of the published literature 2008-2012. The International Review of Research in Open and Distributed Learning, 14(3), 202-227.

Lockwood, F. (2018). The design and production of self-instructional materials. Routledge.

Lwin, H. H., Khaing, A. S., \& Tun, H. M. (2016). Automatic door access system using face recognition. International Journal of Scientific \& Technology Research, 4(6), 210-221.

Martin, F., Wang, C., \& Sadaf, A. (2018). Student perception of helpfulness of facilitation strategies that enhance instructor presence, connectedness, engagement and learning in online courses. The Internet and Higher Education, 37, 52-65.

Newberry, R. (2013). Building a foundation for success through student services for online learners. Online Learning Journal, 17(4).

Norman, H., Nordin, N., Din, R., Ally, M., \& Dogan, H. (2015). Exploring the roles of social participation in mobile social media learning: A social network analysis. International Review of Research in Open and Distributed Learning, 16(4), 205-224.

Ortagus, J. C. (2017). From the periphery to prominence: An examination of the changing profile of online students in American higher education. The Internet and Higher Education, 32, 47-57.

Ozgol, M., Sarikaya, I., \& Ozturk, M. (2017). Students' and teaching staff's assessments regarding distance education applications in formal education. Journal of Higher Education and Science, 7(2), 294304.

Rae, M. G., \& O’Malley, D. (2017). Using an online student response system, Socrative, to facilitate active learning of Physiology by first year graduate entry to medicine students: a feasibility study. MedEdPublish, 6(1), 1-17.

Rumble, G. (2019). The planning and management of distance education. Routledge.

Sadera, W. A., Robertson, J., Song, L., \& Midon, M. N. (2009). The role of community in online learning success. Journal of Online Learning and Teaching, 5(2), 277-284.

Salzmann, C., Piguet, Y., \& Gillet, D. (2019). New Tools for MOOC/MOOL to Sustain Continuity of Experimentation in Control. IFAC-PapersOnLine, 52(9), 254-259.

Samson, P. J., Czarnik, A., \& Gross, M. (2017). Relationships Between Digital Measures of Student Engagement and Exam Scores: Is the LMS Enough? Practitioner Track Proceedings.

Saxena, S., Sharma, S., \& Sharma, N. (2016). Research Article Parallel Image Processing Techniques, Benefits and Limitations. Research Journal of Applied Sciences, Engineering and Technology, 12(2), 223-238.

Shelton, B. E., Hung, J.-L., \& Lowenthal, P. R. (2017). Predicting student success by modeling student interaction in asynchronous online courses. Distance Education, 38(1), 59-69.

Shin, W. S., \& Kang, M. (2015). The use of a mobile learning management system at an online university and its effect on learning satisfaction and achievement. International Review of Research in Open and Distributed Learning, 16(3), 110-130. 
Simonson, M., Zvacek, S. M., \& Smaldino, S. (2019). Teaching and Learning at a Distance: Foundations of Distance Education 7 th Edition. IAP.

Stovall, M. L. (2000). Relationships between participation in a community college student success course and academic performance and persistence.

Vanslambrouck, S., Zhu, C., Lombaerts, K., Philipsen, B., \& Tondeur, J. (2018). Students' motivation and subjective task value of participating in online and blended learning environments. The Internet and Higher Education, 36, 33-40.

Walker, D. S., Lindner, J. R., Murphrey, T. P., \& Dooley, K. (2016). Learning management system usage. Quarterly Review of Distance Education, 17(2), 41-50.

Wilson, G., \& Pretorius, R. W. (2017). Utilising Work-Integrated Learning to enhance student participation and engagement in sustainability issues in open and distance learning. In Handbook of theory and practice of sustainable development in higher education (pp. 245-257). Springer.

Yukselturk, E., \& Bulut, S. (2007). Predictors for student success in an online course. Journal of Educational Technology \& Society, 10(2), 71-83.

Zheng, Y., Wang, J., Doll, W., Deng, X., \& Williams, M. (2018). The impact of organisational support, technical support, and self-efficacy on faculty perceived benefits of using learning management system. Behaviour \& Information Technology, 37(4), 311-319. 